\title{
PERAN SELF-ESTEEM DAN SCHOOL WELL-BEING PADA RESILIENSI SISWA SMK PARIWISATA A
}

\author{
Laksmiari Saraswati $^{1}$, Sri Tiatri ${ }^{2}$, Riana Sahrani ${ }^{3}$ \\ ${ }^{1}$ Program Studi Magister Psikologi, Universitas Tarumanagara Jakarta \\ Email:astisaraswati@gmail.com \\ 2 Program Studi Magister Psikologi, Universitas Tarumanagara Jakarta \\ Email: sri.tiatri@gmail.com \\ ${ }^{3}$ Program Studi Teknik Magister Psikologi, Universitas Tarumanagara Jakarta \\ Email: riana.1123@gmail.com
}

\begin{abstract}
ABSTRAK
Pekerjaan dalam bidang pariwisata menuntut pekerja memiliki kompetensi utama hospitality, termasuk menerima komplain pelanggan dengan positif. Komplain pelanggan berpotensi menimbulkan tekanan emosional. Lulusan SMK Pariwisata A yang masih remaja perlu tangguh dalam menghadapi tekanan dan mampu bangkit kembali dari kegagalan dan memperoleh makna (resiliensi). Resiliensi merupakan inner strength, dapat dipelajari dan dibangun di sekolah. Penelitian ini bertujuan mengkaji peran self-esteem dan school well-being terhadap resiliensi. Partisipan adalah 73 siswa dari SMK Pariwisata A. Data dikumpulkan melalui kuisioner. Hasil penelitian menyatakan bahwa secara bersamaan self-esteem dan school well-being berperan pada resiliensi siswa. Secara terpisah hanya selfesteem yg berperan signifikan pada resiliensi. Artinya dalam membangun resiliensi dibutuhkan peran dari selfesteem dan school well-being secara bersamaan. Kedua hal ini harus difasilitasi oleh pihak sekolah secara keseluruhan sehingga siswa SMK Pariwisata A setelah lulus sudah memiliki ketrampilan untuk menghadapi tantangan pekerjaan.
\end{abstract}

Kata kunci: resiliensi, self-esteem, school well-being, sekolah menengah kejuruan.

\section{PENDAHULUAN}

Persaingan tenaga kerja semakin terbuka seiring dengan pemberlakuan Mayarakat Ekonomi Asean sejak akhir 2015 (Kementerian Pendidikan dan Kebudayaan, Direktorat Pembinaan Sekolah Menengah Kejuruan, 2016c). Terdapat beragam tantangan yang sedang dan akan dihadapi oleh manusia Indonesia, tidak hanya tantangan yang berasal dari dalam negeri, namun juga tantangan global (Universitas Gajah Mada, Pusat Studi Kependudukan dan Kebijakan, 2015). Salah satu sektor yang menjadi fokus dan pengembangan oleh pemerintah adalah sektor Pariwisata. Pekerjaan dalam bidang pariwisata menuntut pekerja memiliki kompetensi utama hospitality, termasuk menerima komplain pelanggan dengan positif. Komplain pelanggan berpotensi menimbulkan tekanan emosional. Antropolog Pande Made Kutanegara menyebutkan bahwa agar mampu menjawab tantangan global, sumber daya manusia Indonesia harus tangguh (Universitas Gajah Mada, Pusat Studi Kependudukan dan Kebijakan, 2015). Dalam bekerja, individu sebagai sumber daya manusia membutuhkan resiliensi dalam menghadapi perubahan industri, teknologi, yang merupakan bagian dari perkembangan pasar global (Reivich \& Sahtte, 2002).

Resiliensi merupakan daya lenting atau kekenyalan mental seseorang dalam menghadapi tekanan. Resiliensi bukan sekadar ketangguhan atau ketahanan seseorang dalam menghadapi tekanan atau tantangan hidup, melainkan kemampuan diri untuk mengatasi, kemampuan untuk kembali bangkit dari keterpurukan, dapat memperoleh manfaat yang bermakna dari pengalaman tersebut sehingga mencapai prestasi yang lebih baik (Satiadarma, 2014). Oleh karena itu, diharapkan resiliensi menjadi faktor yang dapat dimiliki tenaga kerja karena workforce resilience (resiliensi pada tenaga kerja) memiliki manfaat jangka panjang bagi para pekerja itu sendiri 
(Colvin \& Taylor, 2012). Sumber daya manusia yang dibutuhkan oleh perusahaan adalah sumber daya manusia yang memiliki kemampuan untuk bangkit kembali dari kegagalan, dan mampu bertahan dalam menjalani kegagalan yang berulang dalam pekerjaan, seiring dengan proses dan dunia bekerja yang menjadi semakin lebih menantang. Hal ini membuat beberapa perusahaan membutuhkan adanya faktor resiliensi pada sumber daya manusianya (Leiter, 2005). Oleh karena itu, resiliensi menjadi salah satu faktor yang penting untuk dimiliki dalam menghadapi dunia kerja.

Sekolah Menengah Kejuruan (SMK) merupakan salah satu sektor pendidikan yang harus dipertajam dan dikuatkan (Kementerian Pendidikan dan Kebudayaan, Direktorat Pembinaan Sekolah Menengah Kejuruan, 2016b). SMK merupakan bagian dari sistem pendidikan formal, yang memiliki tujuan pendidikan sebagai pendidikan kejuruan, merupakan pendidikan menengah yang mempersiapkan peserta didik terutama untuk bekerja di bidang tertentu, sehingga pendidikan kejuruan sebagai salah satu bagian dari sistem pendidikan nasional memainkan peran yang sangat strategis bagi terwujudnya angkatan tenaga kerja nasional yang terampil dan siap kerja setelah lulus sekolah, dinyatakan dalam Tujuan Pendidikan SMK menurut Undang-Undang Sistem Pendidikan Nasional No. 20 Tahun 2003 pasal 3 mengenai Tujuan Pendidikan Nasional (Istiqomah, 2016). Prioritas pengembangan SMK dipilih berdasarkan kebutuhan terbanyak Indonesia, yaitu SMK bidang Kemaritiman, Pariwisata, Pertanian dan Industri Kreatif (Kementerian Pendidikan dan Kebudayaan, Direktorat Pembinaan Sekolah Menengah Kejuruan, 2016b). Lulusan SMK Pariwisata A yang masih remaja perlu tangguh dalam menghadapi tekanan dan mampu bangkit kembali dari kegagalan dan memperoleh makna (resiliensi).

Resiliensi adalah hal yang dapat dipelajari (Reivich \& Shatte, 2002), dan sekolah merupakan salah satu tempat yang dapat memfasilitasi perkembangan resiliensi seseorang. Dalam konteks sekolah, tingkat resiliensi akademis saling berpengaruh dengan 3 faktor yang terkait dalam psikologi dan pendidikan yaitu (1) kesenangan atau menikmati sekolah, (2) partisipasi didalam kelas, dan (3) self-esteem (Martin \& Marsh, 2006). Moris Rosenberg (dikutip dalam Mruk, 2006) menyatakan bahwa self-esteem adalah evaluasi diri seseorang terhadap kualitas dan keberhargaan diri sebagai manusia. Pengalaman keberhasil dan kegagalan yang dialami seseorang individu dalam hidupnya, akan mempengaruhi tinggi rendah self-esteem nya (Coopersmith dalam Mruk, 2006).

Selain self-esteem, bagaimana seorang siswa merasa senang atau menikmati sekolah mempengaruhi tingat resiliensi siswa tersebut (Martin \& Marsh, 2006). Suasana kondusif di sekolah sangat diperlukan untuk menunjang sekolah yang efektif, karena sekolah adalah suatu tempat yang didalamnya terjadi hubungan saling ketergantungan antara manusia dengan lingkungannya. Sekolah yang kondusif adalah tempat yang menyenangkan bagi manusia yang berinteraksi didalamnya, baik siswa, guru, tenaga pendidik, orangtua siswa dan pelaku lainnya. Ketersediaan sarana dan prasarana pendidikan yang memadai juga menjadi faktor pendukung. Faktor pendukung lain yang penting adalah kepala sekolah yang memimpin para individu didalam sekolah dalam menghadapi dan menyelesaikan masalah (Kementerian Pendidikan dan Kebudayaan, Direktorat Pembinaan Sekolah Menengah Kejuruan, 2016a).

Bagaimana seorang siswa merasa memiliki sekolah, merasa dicintai dan mencintai sekolah, merasa sekolah telah membuat siswa menjadi seorang yang bermakna, dan bagaimana sekolah dianggap dapat memfasilitasi kesehatan siswa, adalah penilaian subjektif siswa terhadap keadaan sekolahnya yang meliputi having, loving, being, dan health yang tercakup dalam sebuah konsep yang disebut school well-being (Konu \& Rimpelä, 2002). Penilian seorang siswa terhadap 
keempat hal ini, secara tidak langsung dipengaruhi oleh kondusivitas dari sekolah tersebut. Pada saat sekolah sudah dapat menyediakan lingkungan yang positif untuk siswanya agar para siswa merasa nyaman dan diterima oleh lingkungannya, maka siswa akan juga merasa nyaman diterima, dan akan merasa senang menikmati sekolah, sehingga secara langsung sekolah memfasilitasi pertumbuhan resiliensi siswanya. Terdapat banyak cara bagi sekolah untuk meningkatkan tingkat resiliensi siswanya. Hal ini membutuhkan pendekatan keseluruhan dari seluruh bagian sekolah untuk menciptakan lingkungan belajar yang aman dan suportif, hubungan yang nyaman antara guru, siswa dan sesama siswa, menciptakan lingkungan belajar yang nyaman di kelas, diberikan program pengembangan sosial dan emosional, serta melibatkan siswa dan orangtuanya dalam pengambilan keputusan (Victoria State Government, Training and Education, 2015).

Tinggi rendahnya tingkat resiliensi teruji pada saat siswa SMK masuk ke dunia kerja yang kompetitif, pada saat siswa mengalami tekanan atau tantangan hidup. Agar dapat menghadapi tekanan tersebut, siswa diharapkan memiliki kemampuan dan ketrampilan diri untuk mengatasi, kemampuan dan ketrampilan untuk kembali bangkit dari keterpurukan. Sekolah diharapkan mampu memfasilitasi ketrampilan psikologis siswa agar memiliki inner strength, dan siswa mampu memperoleh manfaat yang bermakna dari pengalaman tersebut sehingga mencapai prestasi yang lebih baik. Sekolah merupakan key setting dalam mempromosikan kesejahteraan (well-being) dan resiliensi sebagaimana sekolah mempromosikan proses belajar akademis. Terdapat perkembangan dari bukti nyata (evidence based) yang ditemukan di sekolah dalam area resiliensi ini. Bukti nyata yang utama adalah pentingnya pendekatan seluruh sekolah (wholeschool approach) dalam mempromosikan kesejahteraan dan resiliesi siswa. Bukti nyata ini mengidentifikasi beberapa cara yang secara praktis dianggap berhasil dan memberikan pengaruh pada peningkatan kesejahteraan siswa, antara lain pentingnya kontribusi seorang guru yang mampu membuat siswanya merasa sejahtera dengan cara keterlibatan positif dengan siswa dan bagaimana kurikulum dapat membangun resiliensi siswa melalui kurikulum yang mempertimbangkan faktor sosial dan emosional (Victoria State Government, Training and Education, 2015).

\section{METODE PENELITIAN}

Penelitian ini bertujuan mengkaji peran self-esteem (independent variabel 1) dan school wellbeing (independent variabel 2) terhadap resiliensi (dependen variabel). Partisipan adalah 73 siswa dari SMK Pariwisata A. Data dikumpulkan melalui kuisioner.

\section{HASIL DAN PEMBAHASAN}

Berdasarkan perhitungan nilai regresi dari self-esteem dan school wellbeing pada resiliensi diperoleh juga nilai $\mathrm{R}=0,701$, koefisien determinasi $\mathrm{R}^{2}=0,491$, nilai ini diperoleh dari pengkuadratan dari koefisien korelasi $(0,491$ x 0,491). Hal ini juga menujukkan Indeks Determinasi, yaitu persentase yang menyumbangkan peran self-esteem dan school well-being terhadap resiliensi. $\mathrm{R}^{2}=0,491$ mengandung pengertian bahwa 49,1\% sumbangan self-esteem dan school wellbeing terhadap resiliensi sedangkan sisanya sebesar 50,9\% dipengaruhi faktor lain $(100 \%-49,1 \%=50,9 \%)$.

Selanjutnya dari analisis regresi juga dapat diamati bahwa nilai $F=33,779$ dan $p=0.000$ $<0.05$ artinya terdapat pengaruh variabel self-esteem dan school wellbeing terhadap resiliensi. Selanjutnya dari analisis regresi juga dapat dilihat variabel apa yang paling memengaruhi resiliensi. Hal tersebut dapat dilihat dari nilai Beta, untuk self-esteem nilai standardized 
coefficients $($ Beta $)=0,689$ dan untuk school wellbeing nilai standardized coefficients (Beta) $=$ 0,027. Jadi yang lebih besar pengaruhnya terhadap perilaku resiliensi adalah self-esteem.

Selanjutnya diperoleh data self-esteem memiliki nilai $\mathrm{t}=7,314$ dan $\mathrm{p}=0.000<0.05$ artinya H0 ditolak dan $\mathrm{H} 1$ diterima. Jadi terdapat pengaruh yang signifikan dari self-esteem terhadap resiliensi. Selanjutnya juga diperoleh data school wellbeing memiliki nilai $t=0,286$ dan $\mathrm{p}=$ $0.776>0,05$ artinya $\mathrm{H} 0$ diterima dan $\mathrm{H} 1$ ditolak. Jadi tidak terdapat pengaruh yang signifikan dari school wellbeing terhadap resiliensi. Berdasarkan data yang diperoleh, dilakukan uji pengaruh pada empat dimensi school wellbeing dengan variabel resiliensi dan diperoleh data berbagai macam besarnya pengaruh. Dari hasil regresi diketahui bahwa besarnya pengaruh dengan melihat nilai $\mathrm{R}^{2}=0,177$ dan nilai $\mathrm{F}=3,652(\mathrm{p}=0,009<0,05)$. Jadi besarnya pengaruh school wellbeing terhadap resiliensi hanya sebesar $17,7 \%$ dan sisanya $82,3 \%$ dipengaruhi faktor lain. Analisis regresi pertama dilakukan pada dimensi having terhadap resiliensi. Dimensi having memiliki nilai Beta $=0,020, \mathrm{t}=0,215, \mathrm{p}=0,831>0,05$. Hal ini berarti tidak ada pengaruh signifikan dari dimensi having dalam variabel school wellbeing pada variabel resiliensi. Dimensi kedua school wellbeing adalah loving, memiliki nilai Beta $=0,002, \mathrm{t}=0,019, \mathrm{p}=0,985>0,05$. Hasil ini berarti tidak ada pengaruh signifikan dari dimensi loving dalam variabel school wellbeing pada variabel resiliensi.

Dimensi ketiga pada variabel school wellbeing adalah being, memiliki nilai Beta $=0.364, \mathrm{t}=$ $3,048, \mathrm{p}=0,003<0,05$. Hasil ini meyatakan bahwa ada pengaruh signifikan dari dimensi being dalam variabel school wellbeing terhadap variabel resiliensi, artinya dimensi being secara signifikan mempengaruhi resiliensi. Dimensi Health sebagai dimensi keeempat dalam variabel school wellbeing memiliki nilai Beta $=0,073, \mathrm{t}=0,760, \mathrm{p}=0,450>0,05$. Hasil ini berarti tidak ada pengaruh signifikan dari dimensi health dalam variabel school wellbeing pada variabel resiliensi. Gambaran ini menjelaskan bahwa dimensi school wellbeing secara signifikan tidak mempengaruhi resiliensi, tetapi dalam dimensi school wellbeing terdapat satu dimensi yang mempengaruhi resiliensi secara signifikan yaitu dimensi being

Hasil penelitian menyatakan bahwa secara bersamaan self-esteem dan school well-being berperan pada resiliensi siswa. Secara terpisah hanya self-esteem yg berperan signifikan pada resiliensi. Artinya dalam membangun resiliensi dibutuhkan peran dari self-esteem dan school well-being secara bersamaan.

\section{KESIMPULAN}

Terdapat tiga hal utama yang dihasilkan dari pengolahan data pada penelitian ini. Pertama, secara simultan terdapat pengaruh signifikan dari self-esteem dan school wellbeing terhadap resiliensi siswa SMK A. Kedua, secara partial terdapat pengaruh signifikan dari self-esteem terhadap variabel resiliensi siswa SMK A. Ketiga, dari empat dimensi yang terdapat dalam variabel school wellbeing, hanya dimensi Being yang signifikan mempengaruhi resiliensi siswa SMK A, yang berarti bahwa kesempatan yang diberikan sekolah untuk siswa dalam proses pemenuhan diri, secara signifikan mempengaruhi resiliensi siswa SMK A.

Tinggi rendahnya tingkat resiliensi dari siswa SMK A dipengaruhi oleh self-esteem dan school wellbeing mereka. Semakin tinggi tingkat resiliensi, semakin tinggi tingkat self-esteem dan school wellbeing siswa, semakin rendah tingkat resiliensi semakin rendah tingkat self-esteem dan school wellbeing siswa. Secara bersamaan kedua variabel self-esteem dan school wellbeing sebagai variabel independen, memberikan dampak pada resiliensi siswa SMK A, dimana 
resiliensi menurut Sosiolog Pande Made Kutanegara, merupakan keharusan dari manusia Indonesia dalam menjawab tantangan global (UGM, 2016). Hasil penelitian ini juga sejalan dengan pernyataan Martin \& Marsh (2006) bahwa resiliensi dan self-esteem secara signifikan saling berpengaruh.

Tinggi rendahnya tingkat resiliensi seseorang berada didalam kontrol individu itu sendiri. Setiap individu mampu mengajarkan diri sendiri untuk mampu menjadi resilien, dan secara langsung memberikan pengaruh pada individu dalam meningkatkan produktivitas dalam bekerja, kebahagiaan, dan hubungan yang baik dengan orang lain. Resiliensi dalam kehidupan seseorang merupakan proses berkelanjutan, yang juga merupakan transformasi dari kesulitan hidup menjadi tantangan, kegagalan menjadi sukses, dan ketidak berdayaan menjadi kekuatan (Reivich \& Shatte, 2002).

Bagaimana seseorang dapat menilai keberhasilan dan kegagalan dirinya sebagai hal yang positif atau negatif dalam hidupnya kemudian dijelaskan oleh Morris Rosenberg (dalam Murk 2006) mengenai gambaran self-esteem. Penilaian seseorang terhadap dirinya tersebut merupakan kumpulan perasaan dimana individu merasa berharga dan merasa dihormati. Jumlah keberhasilan dan kegagalan yang dialami seseorang semasa hidupnya juga kemudian mempengaruhi tingkat self-esteem seseorang (Coopersmith dalam Mruk, 2006).

Kegagalan dan keberhasilan adalah pengalaman yang dimaknai berbeda oleh setiap individu, dapat dilihat sebagai sebuah proges yang berkelanjutan atau sebuah pencapaian yang dilihat dari tingkatan atau levelnya. Bagaimana lingkungan akan memberikan penilaian akan keberhasilan dan kegagalan pada seseorang, secara tidak langsung juga akan mempengaruhi proses perkembangan self-esteem itu sendiri. Dalam school wellbeing, saat seorang siswa yang merasa dirinya dihormati dan merupakan bagian dari sekolah, secara langsung siswa tersebut akan meningkat self-esteem nya (Konu \& Rimpela, 2002). Merasa berharga dan bermakna, merupakan hal yang penting dalam proses pengembangan diri, sehingga bagaimana seorang individu menilai dirinya apakah akan mampu atau tidak dalam menjalankan sesuatu, merupakan sebagian dari faktor yang mempengaruhi tingkat resiliensi seseorang.

Landasan teori diatas dapat menjelaskan hasil penelitian yang menyatakan bahwa mengapa secara simultan self-esteem dan school wellbeing mempengaruhi resiliensi, dan bila secara partial hanya self-esteem yang secara signifikan mempengaruhi resiliensi. Para siswa SMK A yang menjadi responden penelitian dapat dikatan memiliki self-esteem dan resiliensi yang sudah tinggi, tanpa dipengaruhi oleh faktor dari sekolah. Self-esteem dan resiliensi siswa SMK A dapat terbentuk dari rumah, keluarga, atau dari pengalaman-pengalaman hidup lainnya yang telah mereka alami sebelumnya, dan untuk mengetahuinya lebih lanjut perlu diperlukan kajian tersendiri agar alasan terbentuknya self-esteem dan resiliensi tersebut dapat diketahui secara lebih spesifik.

Beberapa dimensi school wellbeing yang tidak signifikan terhadap resiliensi yaitu having, loving dan health adalah dimensi yang dipengaruhi oleh faktor eksternal, dan ketiga faktor ini secara teori tidak berkaitan dengan faktor fasilitas dari sekolah. Wellbeing siswa dalam sekolah, jauh lebih penting dari pencapaian akademis siswa dalam pendidikan (Konu \& Rimpela, 2002), dan dukungan orang dewasa yang berada di sekolah, merupakan dukungan yang dinilai siswa paling penting, dibandingkan dukungan orang dewasa yang berada di rumah dan lingkungan sekitar rumah siswa (Kimberly et.al., 2014). Hal ini perlu disadari oleh pihak sekolah, karena memang kerap menjadi kendala bahwa tidak semua sekolah dapat memberikan kesejahteraan pada 
siswanya, dan proses evaluasi dari pengembangan school wellbeing memang adalah tantangan yang perlu dilaksanakan dari pihak sekolah.

Kajian yang mempromosikan kompetensi sosial dan emosional siswa didalam sekolah lainnya adalah the school kindness. The school kindness berisi hal-hal yang menurut siswa adalah halhal baik yang mereka temukan di sekolah yaitu suportivitas kelas, optimisme, kebahagiaan, prososial dan pencapaian sosial, kepuasan hidup dan self-efficacy akademis (Binfett, Gadermann \& Schonert-Reichl, 2015). Dimensi dari school kindness seperti optimisme dan self-efficacy adalah dimensi yang juga terdapat dalam resiliensi.

Pada hasil studi lainnya, rasa nyaman yang dirasakan oleh siswa di sekolah merupakan emosi positif. Emosi yang positif meningkatkan resiliensi dan kepuasan hidup (life satisfaction) secara simultan (Cohn et.al., 2009). Kepuasan hidup adalah bagaimana seorang individu mengevaluasi positif seluruh kualitas hidupnya dalam sebuah kesatuan (Veenhoven, 1996). Terdapat lima hal yang mempengaruhi kepuasan hidup seorang siswa yaitu (1) keluarga, (2) teman, (3) sekolah, (4) diri sendiri dan (5) lingkungan (Seligson, Huebner \& Valois, 2003). Bagaimana seorang siswa merasa memiliki hubungan yang baik dengan rekan seusianya dan relasi baik dengan orangorang dewasa yang ada di sekolah juga merupakan hal yang paling dominan dalam memprediksi kepuasan hidup siswa tersebut (Gadermann et,al., 2016). Penelitian yang dilakukan pada 1.239 siswa SMP dan SMA di Norwegia, meyatakan self-esteem memiiliki korelasi positif dengan kepuasan hidup siswa (Moksnes \& Eksnes, 2013).

Hal ini dapat diartikan bahwa, penyelenggaraan school wellbeing dan peningkatan self-esteem yang diberikan sekolah pada siswa tidak hanya memiliki keuntungan pada peningkatan resiliensi siswa saja. Kepuasan hidup yang merupakan penilaian positif seseorang terhadap keseluruhan hidupnya berhubungan dengan resiliensi. Artinya, kajian resiliensi yang merupakan modal siswa agar dapat beradaptasi dalam kompetisi Masyarakat Ekonomi Asean perlu dipertimbangkan untuk menjadi bagian dalam kurikulum dan sistem sekolah. Penerapan praktis school wellbeing dan pengembangan self-esteem siswa perlu dikaji lebih mendalam pada penelitian-penelitian selanjtnya.

Dijelaskan lebih lanjut bahwa untuk pengembangannya, faktor school wellbeing merupakan faktor yang ditentukan dari sekolah, sehingga pihak sekolah harus melihat school wellbeing sebagai sebuah kesatuan untuk melengkapi dan menjawab tantangan yang telah ditetapkan oleh Persatuan Bangsa Bangsa (PBB) pada Hak dan Asasi anak yaitu; Pendidikan anak harus mengarah kepada perkembangan kepribadian, bakat dan mental, kecakapan fisik anak untuk memenuhi potensinya. Sehingga secara konkrit, pengembangan school wellbeing dapat dibagi dalam tiga hal yaitu (1) proses mengajar dan pendidikan, (2) proses belajar, dan (3) pengaruh komunitas yang ada di sekitar siswa. Guru, pendidik, dan para profesional di area pendidikan lainnya harus menemukan cara praktis dalam proses pendidikan dan mengajar dalam kaitannya pada peningkatan school wellbeing dari setiap siswa yang ada (Konu \& Rimpela, 2002).

Hasil penelitian ini mengacu pada bagaimana pihak sekolah selanjutnya akan mengembangkan dan mengevaluasi baik sistem organisasi sekolah maupun pengajaran agar sekolah secara signifikan memberikan andil dalam meningkatkan resiliensi siswanya yang memang sangat dibutuhkan untuk menjawab kebutuhan tenaga kerja di masa mendatang. 


\section{Ucapan Terima kasih}

Terima kasih peneliti ucapkan kepada Bapak Drs. Ucup Hardiman, S.Pd, selaku kepala sekolah SMK Kasih Ananda karena telah bekerjasama dan memberikan kepercayaan kepada peneliti dalam proses penelitian. Terima kasih juga diucapkan kepada tim peneliti, Ibu Sri Tiatri PhD., Psikolog. Dan Ibu Dr. Riana Sahrani, M.Si., Psikolog., atas sinergi dan kerjasama dalam penyusunan penelitian.

\section{REFERENSI}

Binfet, J.T., Gadermann, A.M., \& Schonet-Reichel. (2015). Measuring kindness at school: Psychometric properties of a school kindness sclae for children and adolescents. Psychology in the schools, 53, 111-126. doi: 10.1002/pits.21889

Cohn, M.A., Fredrickson, B.L., Stephanie, L.B., Mikels, J.A. \& Conway, A.M. (2009). Happiness unpacked: Positive emotions increase life satisfaction by building resilience. Emotions, 9, 361-368. doi: 10.1037/a0015952

Colvin, H.M. \& Taylor, R.M. (2012). Building a resilient workforce; Opportunities for department of homeland security. Washington DC: The National Academic Press.

Gadermann, A. M., Guhn, M., Schonert-Reichl, K. A., Hymel, S., Thomson, K. \& Hertzman, C. (2016). A population-based study of children's well-being and health: The relative importance of social relationships, Health-Related Activities, and Income. Journal of Happiness Studies, 17, 1847-1872. doi: 10.1007/s 10902-015-9673-1

Istiqomah, N. (2016, Februari). Peran konselor dalam mengembangkan karier siswa Sekolah Menengah Kejuruan (SMK) melalui kewirausahaan sebagai modal di era Masyarakat Ekonomi Asean. Paper presented at Second Asean Seminar of Psychology and Humanity Universitas Negeri Malang, Malang, Indonesia., Retreived from http://mpsi.umm.ac.id/files/file/297\%20-\%20303\%20NANDA\%20ISTIQOMAH.pdf

Kementrian Pendidikan dan Kebudayaan, Direktorat Pembinaan Sekolah Menengah Kejuruan. (2016a). Konsep pembelajaran di sekolah menengah kejuruan. Retreived from https://psmk.kemdikbud.go.id/konten/1869/konsep-pembelajaran-di-sekolah-menengahkejuruan

Kementerian Pendidikan dan Kebudayaan, Direktorat Pembinaan Sekolah Menengah Kejuruan. (2016b). Pendidikan vokasi di indonesia cetak tenaga kerja siap pakai secara global. Retreived from https://psmk.kemdikbud.go.id/konten/1950/majalah-jendela-pendidikandan-kebudayaan-edisi-september

Kementerian Pendidikan dan Kebudayaan, Direktorat Pembinaan Sekolah Menengah Kejuruan. (2016c). Rencana strategis direktorat pembinaan SMK 2015-2019. Retreived from https://psmk.kemdikbud.go.id/konten/1560/rencana-strategis-direktorat-pembinaan-smk

Kementerian Pendidikan dan Kebudayaan, Direktorat Pembinaan Sekolah Menengah Kejuruan. (2016d) START : Materi ajar bagi guru SMK untuk proses transisi dunia kerja. Retreived from https://psmk.kemdikbud.go.id/konten/1631/start-materi-ajar-bagi-guru-smk-untukproses-transisi-dunia-kerja

Konu, A. \& Rimpela, M. (2002). Well-being in schools: a conceptual model. Health Promotion International, 17 (1), 79-87. doi: 10.1093/heapro/17.1.79

Leiter, M. P., (2005). Resilience at work. E-Journal of The Nova Scotia Psychologist, 16 (Winter) (3), 3. Retreived from http://www.apns.ca/documents/Winter2005.pdf

Martin, A.J., \& Marsh, H.W. (2006), Academic resilience and its psychological and educational correlates: A construct validity approach, Psychology in the Schools, 43 (3), 267-281, doi: 10.1002/pits.20149 
Moksnes, U. K., \& Epsnes, G. A. (2013). Self-esteem and life satisfaction in adolescents-gender and age as potential moderators. Quality of Life Research, 22, 10, doi: 10.1007/s11136013-0427-4

Mruk, C. J. (2006). Self-esteem research, theory, and practice: Toward a positive psychology of self-esteem. New York: Springer Pub.

Reivich, K. \& Shatte, A., (2002). The resilience factor; 7 essential skill for overcoming life's inevitable obstacle. New York: Broadway Books.

Satiadarma, M.P., Siregar, A.F. \& Dwiariani, D.A (2014). Rahasia ketangguhan mental juara Christian Hadinata. Jakarta : Kepustakaan Populer Gramedia.

Seglison, J. L., Huebner, E. S. \& Valois, R. F. (2003). Preliminary validation of the brief multidimensional students' life satisfaction scale (BMSLSS). Social Indicatorr Research, February 2003, 61, 121-145. doi: 10.1023/A:1021326822957

Universitas Gajah Mada, Pusat Studi Kependudukan dan Kebijakan. (2015). Hadapi tantangan MEA 2015, manusia indonesia harus tangguh. Retreived from http://cpps.ugm.ac.id/hadapi-tantangan-mea-2015-manusia-indonesia-harus-tangguh/

Veenhoven, R. (1996). The study of life-satisfaction. In W.E. Saris, R. Veenhoven, A.C. Scherpenzeel \& B. Bunting (Eds), Comparative Study of Satisfaction with Life in Europe (pp 11-48). Hungary, Budapest: Eötvös University Press.

Victoria State Government, Training and Education. (2015). Building resilience: A model to support children and young people. Retreived from http://www.education.vic.gov.au/about/department/Pages/resiliencelitreview.aspx 